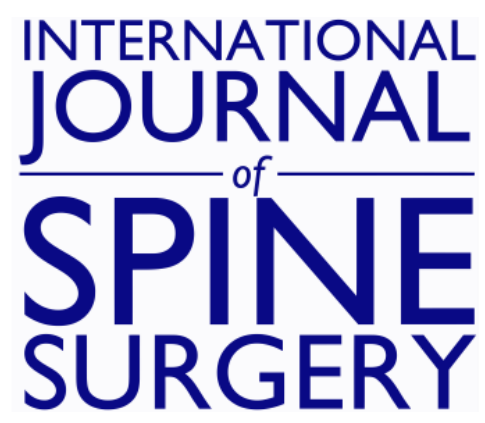

\title{
Special Considerations to Improve Clinical Outcomes in Patients with Osteoporosis Undergoing Spine Surgery
}

Brian Fiani, Alexander Newhouse, Kasra John Sarhadi, Mohammad Arshad, Marisol Soula and Alessandra Cathel

Int J Spine Surg 2021, 15 (2) 386-401

doi: https://doi.org/10.14444/8050

http://ijssurgery.com/content/15/2/386

This information is current as of April 26, 2023.

Email Alerts Receive free email-alerts when new articles cite this article. Sign up at:

http://ijssurgery.com/alerts

The International Journal of Spine Surgery

2397 Waterbury Circle, Suite 1,

Aurora, IL 60504, Phone: +1-630-375-1432 


\title{
Special Considerations to Improve Clinical Outcomes in Patients with Osteoporosis Undergoing Spine Surgery
}

\author{
BRIAN FIANI, DO, ${ }^{1}$ ALEXANDER NEWHOUSE, BS, ${ }^{2}$ KASRA JOHN SARHADI, MD, MPH, ${ }^{3}$ \\ MOHAMMAD ARSHAD, DO, ${ }^{1}$ MARISOL SOULA, BS, ${ }^{4}$ ALESSANDRA CATHEL, DO ${ }^{1}$ \\ ${ }^{I}$ Department of Neurosurgery, Desert Regional Medical Center, Palm Springs, California, ${ }^{2}$ Department of Orthopedic Surgery, Rush University Medical Center, \\ Chicago, Illinois, ${ }^{3}$ Department of Neurology, University of Washington, Seattle, Washington, ${ }^{4}$ New York University School of Medicine, New York University, \\ New York, New York
}

\begin{abstract}
Background: Osteoporosis is a condition that is commonly encountered, with increasing diagnosis by the medical community with the aging population. Osteoporosis leaves patients susceptible to fragility fractures in the vertebrae and is also associated with degenerative changes, both of which may require intervention from a spine surgeon. The goal of this review is to concisely outline special nonoperative adjuncts, as well as preoperative, intraoperative, and postoperative considerations of osteoporotic patients undergoing spine intervention.

Methods: A literature analysis was completed for this narrative review. A database search of PubMed and Google Scholar was conducted using "osteoporosis" combined with "spine," "spine surgery," and "spinal fusion" without exclusion based on publication date. Articles were screened to exclude duplicate articles and screened for their full text and English language availability.

Results: The database search yielded recent publications from which the narrative review was completed.

Conclusions: Preoperatively, screening is traditionally completed with dual-energy x-ray absorptiometry (DEXA). Pharmacological therapy modalities currently include teriparatide, raloxifene, denosumab, bisphosphonates, and calcitonin. In order to prevent operative complications associated with osteoporosis, surgeons have found success in increasing the diameter and the length of pedicle screws, limiting pedicle tapping, achieving bicortical or even tricortical purchase, augmenting with polymethyl methacrylate, using iliosacral stabilization, preventing positive sagittal balance, and using adequate fusion products when necessary. Postoperatively, it is important to implant a care plan that includes adequate pain control and necessary care, and to understand risks associated with falls may increase risk of postoperative fragility fractures as well as instrumentation displacement. At this time there are no recommendations in regard to bracing in the postoperative setting.

Clinical Relevance: This review article outlines the most current evidence-based medicine with regard to considerations in spine surgery of the osteoporotic patient, and aims to bring about new questions to be investigated in that paradigm.
\end{abstract}

Other \& Special Categories

Keywords: osteoporosis, spinal fusion, geriatric, spine surgery, outcomes

\section{INTRODUCTION}

According to the National Osteoporosis Foundation over 50 million Americans have low bone density. This is measured by a decrease in the bone mass per unit volume (volumetric density, $\mathrm{g} / \mathrm{cm}^{3}$ ) or per unit area (areal density, $\mathrm{g} / \mathrm{cm}^{2}$ ) and can be the primary reason for an osteoporotic fracture. Fifty percent of individuals older than 50 years of age are at risk for osteoporotic fractures that can significantly increase mortality and morbidity. ${ }^{1}$ Low bone density can ensue when there is an imbalance between bone resorption and formation. Several factors contribute to the prevalence and severity of losing bone mass, such as female sex, tobacco use, alcoholism, older age, genetics, and poor nutrition. Consequently, this skeletal fragility increases a patient's susceptibility to fractures. Approximately $14 \%$ of males and $40 \%$ of females over the age of 50 will suffer from an osteoporotic fracture. ${ }^{2}$ Of these fractures, the highest incidence and prevalence are those involving the spine. An estimated 1.5 million vertebral fractures occur every year in the elderly population and usually in the thoracolumbar junction. ${ }^{3}$ With an ever-growing geriatric population, the health care system is susceptible to an increased financial burden. It is expected that osteoporotic fractures will have an estimated annual 
economic burden of over $\$ 25.3$ billion by $2025 .{ }^{3} \mathrm{We}$ can mitigate these projected outcomes by preventing, diagnosing, and treating patients before fractures occur.

The basic multicellular unit in the context of osteoporosis consists of osteoclasts, osteoblasts, osteocytes, and bone-lining cells. The skeleton is constantly undergoing remodeling, which incorporates both bone deposition (positive balance) and bone resorption (negative balance). If the basic multicellular unit is compromised toward a state of sustained negative balance, a state of osteopenia and, ultimately, osteoporosis may ensue. Bone mineral density (BMD) has traditionally been an indicator of bone metabolism and turnover. ${ }^{4}$

Osteoporosis is the most severe form of decreased BMD. It is characterized as 2.5 standard deviations below the average population BMD ( $\mathrm{T}$ score less than 2.5). ${ }^{5}$ Osteopenia is a range of bone loss between normal BMD and osteoporosis. Since osteoporosis is generally a disease of the geriatric population, screening is recommended by the United States Preventive Services Task Force for women above the age of 65 . Screening for osteoporosis entails calculating the BMD by imaging protocols of the hip and spine. The most common technique is dual-energy $\mathrm{x}$-ray absorptiometry (DEXA), which takes advantage of an x-ray's sensitivity to the calcium found in bone. Other radiographic techniques such as quantitative ultrasound and computed tomography (CT) can be applied in certain instances. ${ }^{6}$ Osteopenia is considered an early stage of osteoporosis based on BMD measurements, and optimistically, before any decrease in bone mass, interventions should be implemented. Thus, a fracture can be avoided by regular counseling, lifestyle changes, vitamin D and calcium supplementation, physical activity, and pharmacological intervention (ie, bisphosphonates).

\section{Preoperative Considerations}

There are 3 types of osteoporosis: postmenopausal, senile, and secondary osteoporosis. Postmenopausal osteoporosis includes women who are 50-60 years of age or men with hypogonadism. As estrogen and testosterone are bone protective by stimulating apoptosis in osteoclasts, attenuation of these will shift bone metabolism toward negative balance. ${ }^{7}$ Senile osteoporosis includes both men and women above the age of 70 . There is an overall decrease in body mass index (BMI) that occurs with aging and associated decrease in protein production, as well as a decrease in the hydroxyapatite necessary for bone remodeling. ${ }^{8}$ Okuda et $\mathrm{al}^{9}$ found that patients older than 70 years of age who underwent posterior lumber interbody had a higher rate of delayed union than those who were younger. Secondary osteoporosis includes patients who have an underlying medical or iatrogenic condition resulting in decreased BMD. For example, hormones such as parathyroid hormone $(\mathrm{PTH})$ or glucocorticoids play a role in decreasing BMD by increasing rate of calcium resorption or decreasing production of hydroxyapatite, respectively. ${ }^{8}$

Risk factors for osteoporosis include history of nonpathological fragility fractures of the wrist, hip, spine, or proximal humerus; current cigarette use; excessive alcohol consumption; family history of osteoporosis or fragility fractures; low BMI; rheumatoid arthritis; kidney transplant; hypogonadism; sedentary lifestyle; chronic glucocorticoid use; chronic renal failure; hypovitaminosis D; gastrointestinal malabsorption or eating disorder; and exaggerated thoracic kyphosis. ${ }^{10-12}$

Prior to spine surgery, risk factors for osteoporosis should be reviewed with the patient and reduction of modifiable risk factors should be attempted (ie, cigarette smoking). ${ }^{8}$ Increasing peak bone mass with adequate intake of calories as well as calcium and vitamin D along with resistance exercises may prevent progression to osteoporosis. ${ }^{10}$ Low levels of $25(\mathrm{OH})$ vitamin D (25OHD) are found in $40 \%-90 \%$ of adults and is strongly associated with osteoporosis. Risk factors for hypovitaminosis $\mathrm{D}$ include age greater than 50 years, current tobacco use, BMI greater than 30, and lack of vitamin supplementation. ${ }^{8}$ Additionally, patients with osteoporosis undergoing spine surgery should be counseled on potential risks and complications (Table 1).

\section{Diagnostic Modalities and Radiographic Findings}

Nonradiographic evaluation of osteoporosis includes bone turnover markers, which include, but are not limited to, serum alkaline phosphatase, serum osteocalcin, serum calcium and phosphate, serum 25OHD, and urine collagen cross-linked degradation products. Calcium and phosphate levels also provide insight on potential etiology of osteoporosis. ${ }^{10}$ Currently, bone turnover markers are not recommended for routine diagnostic purposes because they have not demonstrated predic- 
Table 1. Nonmodifiable and modifiable risk factors for osteoporosis when considering preoperative optimization of patient for spine surgery.

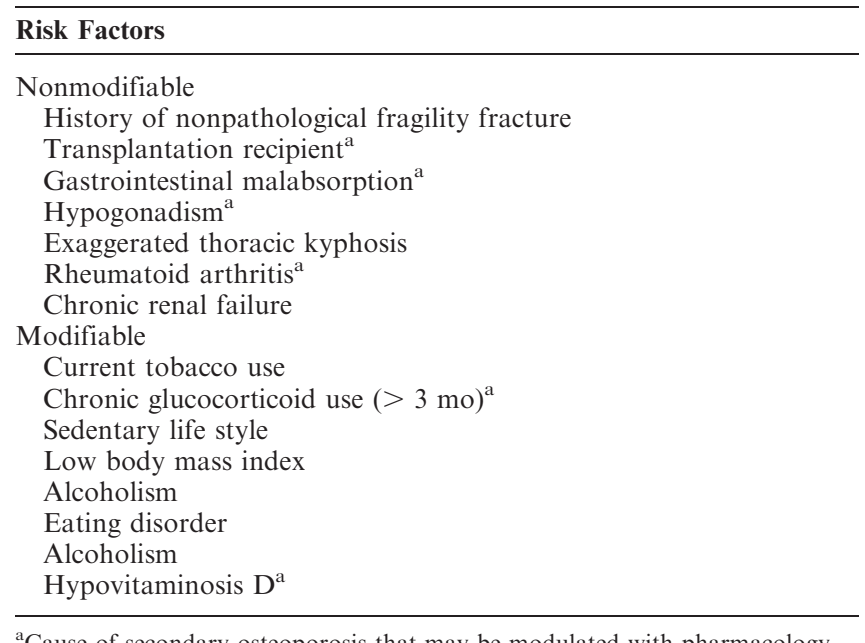

tive value of bone mass or fracture risk. ${ }^{13}$ However, certain bone turnover factors such as procollagen type 1 and tartrate-resistant acid phosphatase 5b have been shown to be associated with risk for nonunion. ${ }^{14}$ Clinically, the best established use for using biomarkers is to monitor medical intervention. There is a significant reduction in bone resorption markers within 4 to 6 weeks and an increase in bone growth markers in 2 to 3 months after initiating therapy. ${ }^{15}$

In the past BMD was measured with dual-photon absorptiometry, using a ${ }^{153} \mathrm{Gd}$ source. This modality was found to be a sensitive way to measure the agerelated loss of cancellous bone. ${ }^{15}$ This modality, however, has fallen out of favor in use and has largely been replaced by DEXA. The DEXA advantages include a shorter scanning time and higher resolution. DEXA has been shown to be an accurate and reproducible modality to measure BMD in the lumber spine as well as the whole body; however, it is also useful in measuring nonbone lean mass and fat mass, which may be used as a modality in evaluating sarcopenia and cachexia. $^{16}$

DEXA has become the standard of care for initial assessment of BMD as well as follow-up after therapy. ${ }^{10}$ Traditionally, DEXA is used to measure BMD of the proximal femur, distal radius, and lumbar spine in the posterior-anterior plane. Lateral DEXA for the lumbar spine has also been established for a more sensitive measurement of agerelated bone loss; however, the measurements in this plane are not as precise secondary to issues with patient positioning. ${ }^{17}$ The World Health Organiza- tion (WHO) recommends screening for postmenopausal women and patients with risk factors of osteoporosis with DEXA and metabolic panel testing. ${ }^{10,11}$ The American College of Radiology also recommends asymptomatic men aged 70 and older undergoing consideration for spinal surgery to be screened with DEXA. ${ }^{8,11}$ The International Society of Clinical Densitometry has also published guidelines for DEXA screening in premenopausal women, men younger than 50 years of age, and children. $^{12}$

Other modalities for evaluation of BMD include quantitative computed tomography (QCT), quantitative ultrasound (QUS), and measurement of Hounsfield units (HU) on CT of the lumbar spine. QCT techniques exist in both single-slice and volumetric analysis. While volumetric analysis techniques have more precision, they also carry a higher radiation dose than the single-slice technique. $^{12}$ QCT has been shown to have some advantages over DEXA. ${ }^{11,18}$ In the spine, QCT offers a volumetric analysis of trabecular BMD. As the effects of osteoporosis occur earlier and to a greater degree on trabecular bone, QCT is able to detect changes in BMD earlier than DEXA. ${ }^{17}$ Due to is its properties of areal measurement, DEXA may underestimate BMD in patients with a small body frame. ${ }^{12}$ DEXA may also fail to diagnose osteoporosis in patients with obesity, large bony spurs, sclerotic changes of the spine, or aortic calcification. $^{12,18}$ QCT is able to overcome these deficiencies as it can measure the trabecular bone quality without superimposition of cortical bone or other tissues. ${ }^{17,18}$ In the setting of spine surgery, QCT offers information on suitability of bone for interpedicular fixation. It has been demonstrated that BMD less than $90 \mathrm{mg} / \mathrm{mL}$ increases likelihood of early loosening of screws, while BMD greater than $120 \mathrm{mg} / \mathrm{mL}$ makes this less likely. ${ }^{19}$ It has also been shown to be more useful in children. ${ }^{11}$ Limitations of QCT include the high costs and radiation exposure to the patient. ${ }^{18}$ The current recommendations of using QCT over DEXA include patient populations with expected severe degenerative changes of the spine, patients with body habitus of either extreme, or a need for a highsensitivity study to follow metabolic changes in bone from medical therapy. ${ }^{12}$

The HU measurement on CT of the lumbar spine has been shown to have significant correlation with BMD. ${ }^{10,18} \mathrm{HU}$ is a measurement of radio-density 
that is traditionally used by radiologists for interpretative purposes. More dense tissue will have greater absorption of $\mathrm{x}$-rays and will appear brighter on CT imaging. ${ }^{20} \mathrm{Kim}$ et $\mathrm{al}^{18}$ found that HU measurement on lumbar CTs was sensitive $(93.4 \%)$ and specific $(87.5 \%)$ in single measurement to assess BMD in osteoporosis. HU calculation is readily accessible on a picture archiving and communication system. A lumber spine CT is routinely obtained in preparation of spine surgery, use of $\mathrm{HU}$ offers no additional cost or radiation to the patient. ${ }^{18}$

The limitation of BMD measurement has shifted some focus to bone quality with novel imaging biomarkers including high-resolution peripheral QCT, QUS, and magnetic resonance spectroscopy of bone marrow. The high-resolution peripheral QCT has been developed for imaging of the distal radius and tibia. Similar to QCT, it is able to distinguish trabecular and cortical bone; however, it is also able to appreciate the architectural lattice of the aforementioned bone. Structural analysis has shown to be useful in identifying risk of fragility fractures, as well as monitoring therapeutic intervention. QUS is a cost-effective technique, which is performed on the calcaneus to determine the velocity and amplitude of the ultrasound signal. The velocity decreases and amplitude increases with reduced BMD. Although QUS has demonstrated the ability to assess bone quality by predicting fractures, there is low correlation between QUS and DEXA. Currently, QUS is not recommended to diagnose or monitor osteoporosis. Lastly, magnetic resonance spectroscopy may be used as a modality to assess bone quality as it can measure bone marrow fat content, which has been noted to increase with decreasing BMD. ${ }^{12}$

\section{Scoring Systems}

DEXA is currently the standard for measuring BMD in the spine, proximal femur, and distal third of the forearm. The $\mathrm{T}$ score is the standard deviation relative to the BMD of a healthy population. A $\mathrm{T}$ score of the proximal femur or lumbar spine greater than -1 correlates with normal BMD; between -1.5 and -2.5 and less than -2.5 are defined as osteopenia and osteoporosis, respectively. ${ }^{12,19,21}$ In premenopausal women and men under 50 years old, the International Society of Clinical Densitometry has developed Z scores, which compare $\mathrm{BMD}$ of the patient to that of the average
BMD of their age population. A $\mathrm{Z}$ score less than -2 corresponds to BMD below what is expected for the patient's age. ${ }^{12}$

The Fracture Risk Assessment tool (FRAX) is a questionnaire developed by WHO to characterize the 10-year probability of hip fracture or major osteoporosis-related fracture. ${ }^{15,21}$ Although vertebral body fractures occur earlier than, and are twice as common as, hip fractures associated with low BMD, the current WHO guidelines build criteria and FRAX risk based on BMD calculated by posterior-anterior (PA)-DEXA of the femoral neck. ${ }^{12,17}$ The FRAX also considers clinical risk factors that are discussed below and it is only compatible with DEXA. ${ }^{12}$

The American College of Radiology has introduced separate guidelines for the use of QCTmeasured BMD values in evaluation of osteoporosis. BMD values greater than $120 \mathrm{mg} / \mathrm{mL}$ correspond to normal values and BMD values ranging from 120 to $80 \mathrm{mg} / \mathrm{mL}$ and less than $80 \mathrm{mg} / \mathrm{mL}$ correspond to osteopenia and osteoporosis, respectively. ${ }^{12,17} \mathrm{~T}$ scores are not traditionally used for QCT as there would be an overdiagnosis of osteoporosis. $^{12}$ The reasoning for this is 2-fold. First, QCT is more sensitive to the physiologic agerelated changes to bone. With aging, the trabecular bone is first to lose BMD and because QCT measures the trabecular bone separately, these changes will result in larger changes in BMD with aging relative to PA-DEXA measurements. Second, artifacts such as large BMI, prominent osteophytes, and aortic calcifications may falsely elevate PADEXA measurements of BMD. ${ }^{17}$

There are currently no scoring systems that use HU to classify osteoporosis. However, Kim et al ${ }^{18}$ demonstrated that the cutoff values for osteoporosis of HU when compared to QCT and DEXA of the spine were 146 and 95, respectively. The sensitivity and specificity were highest in the QCT comparison group with $94.4 \%$ and $87.5 \%$, respectively. ${ }^{18}$ There are currently no values that have been studied for $\mathrm{HU}$ that describe the range for osteopenia.

\section{Structural Integrity}

Increased bone loss in the spine is most commonly manifested as vertebral fractures. Approximately two thirds of vertebral fractures do not come to clinical attention and are asymptomatic; the remaining present with back pain, height loss, muscle spasm, and other impairment. ${ }^{6}$ Additionally, 
Table 2. A common sequela of osteoporosis includes fragility fractures of vertebral body after mild or moderate trauma. The International Society of Clinical Densitometry has created a grading system for osteoporotic vertebral body fractures from $\mathrm{T} 4$ to $\mathrm{L} 4 .^{11}$

\begin{tabular}{ll}
\hline Grade & \multicolumn{1}{c}{ Description } \\
\hline 0 & No fracture \\
1 & Mild fracture $(20 \%-25 \%$ loss of height $)$ \\
2 & Moderate fracture $(25 \%-40 \%$ loss of height $)$ \\
3 & Severe fracture $(>40 \%$ loss of height $)$ \\
\hline
\end{tabular}

having a previous fracture strongly increases the risk of a subsequent fracture and can lead to chronic pain. The deformities that arise from osteoporoticspecific fractures can be classified into 3 groups. ${ }^{5}$ The most common are wedge fractures that occur by hyperflexion injuries that lead to anterior height loss. In biconcave fractures, the middle portion of the vertebral body collapses with little effect on the anterior and posterior walls. Lastly, crush fractures result in spine collapses that ultimately cause pain, deformity, and loss of height (Table 2). The vast majority of these fractures result from minimal trauma in patients with osteoporosis and can lead to progressive loss of stature, fatigued muscles, vertebral deformities, pulmonary malfunction, protuberant abdomen, and early satiety and weight loss.

Mechanical damage and hormonal changes that occur in the elderly population can affect the bone remodeling process. Factors such as PTH, vitamin $\mathrm{D}$, calcitonin, estrogen, and cytokines are relevant in stimulating bone growth via activation of osteoblasts that lay down new bone. ${ }^{22}$ Factors that influence osteoclasts to resorb old bone include tumor necrosis factor, receptor activator of nuclear factor kappa B, and insulin growth factor- $1 .{ }^{22}$ When these factors are not balanced, bone density is altered, and the trabecular histological microstructure can be seen to be disrupted. Bone density starts to decrease when the trabeculae thin and disconnect from one another to form a more perforated bone. Once a fracture occurs, adipocytes, vasculature, neuronal pathways, and bone marrow are altered and microcalluses can form, thereby further affecting the quality of bone. Additionally, fractures result in the initiation of an active remodeling process. This involves resorption of necrotic bone and cartilage, endochondral bone formation, and revascularization of the area.

When the combination of low bone density and distorted spinal torque are combined, osteoporotic vertebral fractures occur. Axial forces that are greater than the forces the vertebral body can tolerate lead to compression or burst fractures. These fractures alter spine biomechanics, which in turn may result in additional fractures, progressive deformities, and other complications beyond the spine. $^{23}$

\section{Impact of Osteoporosis on Surgical Outcomes}

The decreased BMD of osteoporotic patients not only subjects them to an increased incidence of vertebral degeneration and fracture compared to their nonosteoporotic counterparts, but also makes them a particularly challenging population to undergo spine surgery. These challenges may limit successful outcomes or increase risks of complications. Successful spine surgeries, in all aspects including stabilization, instrumentation, and/or fusion, require optimal BMD in order to achieve adequate fixation strength, long-term stability, and minimization of instrumentation failure. Surgical technique has evolved with new methods to improve surgical outcomes in osteoporotic patients, which will be reviewed in later sections of this publication.

There are various complications that can arise when patients receive spine surgery, some intraoperatively and others that develop postoperatively in the recovery timeline. Although data directly comparing spine surgery outcomes in osteoporotic patients to nonosteoporotic patients are limited, there is evidence that patients with osteoporosis experience various surgical complications, sometimes at a higher rate than their nonosteoporotic counterparts. For example, a review by DeWald and Stanley ${ }^{24}$ surveyed 47 spinal deformity correction procedures in 38 patients and revealed that osteoporotic patients had an incidence of $13 \%$ for early (less than 3 months) postoperative complications, including epidural hematoma with neurological injury secondary to pedicle fracture and surgicalsite-adjacent compression fractures. Delayed (greater than 3 months) postoperative complications in the same group included pseudarthrosis with instrumentation failure (11\%), acute disk herniation above the last instrumented level $(4 \%)$, loosening of instrumentation $(7 \%)$, proximal junctional kyphosis $(26 \%)$, and pelvic fixation prominence $(11 \%){ }^{24} \mathrm{~A}$ separate review surveying interbody fusion procedures in the osteoporotic population reported complications including subsidence, disk space collapse, and delayed union. ${ }^{9}$ In a review of immediate postoperative complications in osteoporotic patients specifically undergoing cervical spine 
surgery, the authors identified a higher rate of hemorrhage (odds ratio [OR] 1.7), an increased mean length of inpatient postoperative stay by one full day, and nearly $30 \%$ higher mean surgeryrelated costs compared to nonosteoporotic patients. $^{25}$

This significant and often increased incidence of complications in osteoporotic patients receiving spinal surgery is both dangerous and often manifests in the increased need for surgical revision. In the literature reviewing spinal fusion procedures, rates of nonunion in both osteoporotic and nonosteoporotic patients have been reported between as low as $5 \%$ and as high as $35 \%{ }^{4}$ Although this range did not demonstrate a clear trend toward increased rates of nonunion in osteoporotic patients, a review of data obtained from the Nationwide Inpatient Sample database (composed of a stratified 20\% sample of annual hospital admissions in the United States) for patients receiving posterior cervical fusion surgery illustrated that revision surgery was performed more frequently in osteoporotic patients compared to nonosteoporotic patients (OR 1.54). ${ }^{25}$ Increased likelihood of the need for spinal surgery revision in osteoporotic patients is a factor of immense importance to consider when deciding whether to follow through with a procedure and subject the patient to more risk of complications. In neurologically intact osteoporotic patients with nonemergent spinal issues, it is prudent to engage in a discussion and shared decision-making with patients about whether pursuing more conservative nonsurgical therapy is more suitable for the patient's long-term benefit.

Altogether, the risk of complications or instrumentation failure posed to osteoporotic patients undergoing spinal surgery not only warrants a higher level of caution in choosing surgical therapies, but also emphasizes the importance of medical optimization of each patient's osteoporosis and other medical comorbidities to ensure the highest possible potential for surgical success.

\section{Special Nonsurgical Considerations}

\section{Endocrinologist Referral}

Consultation of an endocrinologist can play a role to ensure the patient is an appropriate candidate for spine surgery through identification of any osteoporotic risks and management of the underlying condition. Osteoporosis can be secondary to underlying mechanisms such as glucocorticoid-induced hypo- and hyperthyroidism, hypogonadism, diabetes mellitus, and growth hormone deficiency. ${ }^{26}$

Postmenopausal women and men $\geq 50$ years on glucocorticoid therapy should consider osteoporotic treatment for a prior incidental fracture, high therapeutic dosage, or $\mathrm{BMD} \mathrm{T}$ score $\leq 1.5 .^{27}$ Bone-protective pharmacological therapy should be started if a patient is at high risk of fracture when on glucocorticoids and includes alendronate, etidronate, risedronate, zoledronic acid, and teriparatide. ${ }^{27}$ The goal of bone-protective therapy is to reduce the incidence of fractures, and follow-ups with patients must be done to monitor patient compliance and dosage to achieve optimal outcomes.

Hyperthyroidism and hypothyroidism can affect BMD and cause an increase incidence of fracture due to osteoporotic bone. Risk factors for those on treatment include duration of hyper- and hypothyroidism, especially in postmenopausal women. ${ }^{28}$ In patients with high thyroid-stimulating hormone (TSH) levels, the risk of osteoporotic fracture is associated with the duration of high TSH levels prior to treatment. While hypothyroidism can increase bone turnover rate and consequently reduce $\mathrm{BMD}$, the mechanism through which it does so is unclear. ${ }^{28}$ Treatment should prioritize management of TSH levels with concomitant osteoporotic management if the bone turnover and BMD is moderate to severe.

Secondary osteoporosis from hypogonadism occurs in females following estrogen deficiency due to menopause and in males where testosterone levels fall, causing a decrease in BMD and increased risk for osteoporotic fractures. While the mechanism is still unclear, androgen receptors have been associated with osteoblasts, osteoclasts, and osteocytes. $^{29,30}$ Patients with complete and partial androgen insensitivity syndrome show that bone density is lower in the lumbar spine via DEXA, indicating that androgens function in trabecular bone maintenance and density in the absence of estrogen. ${ }^{31}$ Additional literature supports the notion of androgens regulating bone density with deficiency consequentially a factor in contributing to osteoporosis. $^{32-34}$ While hormone replacement can treat androgen deficiency and modifiable physical activity is an alternative, it is debated whether the benefits of pharmacologic treatment outweigh the risks..$^{35,36}$

Osteoporosis in the presence of diabetes mellitus can be a resultant of complex mechanisms that alter 
the bone microstructure, the composition of the marrow, and the functionality of osteocytes. ${ }^{37}$ It is suggested that being hyperglycemic for extended periods of time causes advanced glycation end products to accumulate, reducing bone quality through diminishment of type I collagen and stimulating osteoclast activity via tumor necrosis factor, macrophage colony stimulating factor, and receptor activator of nuclear factor kappa-B ligand. ${ }^{38,39}$ While the mechanisms are multifactorial, the clinical implications are risk for increased incidence of bone fracture, especially for those with a prolonged period of time since diagnosis and glycated hemoglobin A1c levels $\geq 7 \% .^{40-42}$ With multiple pathways contributing to alteration of bone structure and higher fracture risk in diabetic patients, screening of this patient population should be implemented into the preoperative protocol to ensure optimal surgical outcomes.

Growth hormone is critical to achieve appropriate height and BMD throughout adolescence through direct targeting of osteoblasts for bone formation. A deficiency of this hormone can cause skeletal immaturity due to decreased BMD through a loss of osteoblastic activity, putting this population at an increased risk of fracture. ${ }^{43,44}$ Those with growth hormone deficiencies can be more at risk for vertebral deformities, especially with prolonged duration of disease. ${ }^{45}$ Pharmacological treatment entails growth hormone replacement therapy, which has shown to increase bone formation and BMD and lead to a significant decrease of risk in these patients. $^{45,46}$

\section{Vitamin D}

Vitamin $\mathrm{D}$ is commonly taken as a dietary supplement and is converted to its hormonal form called vitamin $\mathrm{D}_{3}$. Vitamin $\mathrm{D}_{3}$ is stimulated by PTH and inhibited by calcium and phosphate. In a vitamin D-deficient state, hyperparathyroidism, hypocalcemia, and hypophosphatemia occur. Secondary hyperparathyroidism can cause accelerated bone turnover and lower bone mineralization. It can be challenging to determine whether bone mineralization loss is solely due to a vitamin D deficiency or whether it is multifactorial. A study from Walker et $\mathrm{al}^{47}$ analyzed BMD and microstructure in patients with and without 25OHD insufficiency and deficiency and failed to find any reduction in skeletal integrity between the two groups. Vitamin D supplementation is a preventative factor in osteo- porosis and fracture risk, a meta-analysis of randomized controlled trials supports the use of calcium and vitamin D supplements to intervene in reducing fracture risk. ${ }^{48}$ Clinical and histomorphometrical evaluation of patients with femoral neck fractures concluded reduced bone volume and trabecular thickness, elevated PTH levels, and lower serum 25OHD levels were present. ${ }^{49}$ While existing literature supports the notion that deficient vitamin $\mathrm{D}$ levels are associated with the presence of bone fractures, it is difficult to suggest whether maintenance of a normal range of vitamin $\mathrm{D}$ maintains bone structure density and structure.

\section{Calcium Supplementation}

Calcium supplementation alone in fracture prevention is not established enough in the literature to offer significant clinical intervention, but when used concomitantly with vitamin D supplements, studies have shown a reduction in fracture prevalence. ${ }^{50,51}$ Supplementary use of calcium with vitamin D has been shown to reduce fracture risk in postmenopausal women and men older than 50 years of age. ${ }^{52}$ This notion is supported by biological rationale that the use of vitamin D supplementation is to facilitate the absorption of calcium since a decrease in calcium levels can cause higher levels of PTH and increased bone turnover. ${ }^{53-55}$ Given the inversely related fluctuations between $25 \mathrm{OHD}$ and $\mathrm{PTH}$, it is important to use supplementation to maintain serum levels of vitamin D and calcium. ${ }^{56}$ Maintaining these levels can be as simple as dietary management, such as incorporation of calciumcontaining supplementation, and can have a profound impact against increased bone resorption and osteoporotic-related fractures. ${ }^{57,58}$

\section{Angiotensin II Receptor Blocker Versus Angiotensin-Converting Enzyme Inhibitor Differences in Fusion Rate}

The renin-angiotensin system functions in the regulation of blood pressure and angiotensin II receptor blockers (ARBs) and angiotensin converting enzyme (ACE) inhibitors are often prescribed for management. Almost $50 \%$ of patients who undergo spinal fusion are hypertensive. ${ }^{59}$ The use of ARBs and ACE inhibitors when undergoing spinal fusion should be considered as predictors for surgical outcomes. Management with ARBs is an indicator for a successful spinal fusion, while those prescribed ACE inhibitors are more likely to 
undergo failure. ${ }^{60}$ ACE inhibitors have been shown to result in significant bone loss in men greater than 65 years and can be considered a preoperative factor for those undergoing surgery. ${ }^{61}$ When assessing fracture risk between ARBs and ACE inhibitors, some studies reported a decreased fracture risk in those taking ARBs with some support concluding no significance in osteoporosis-related fractures between ARBs and ACE inhibitors. ${ }^{62-65}$ When considering a patient for surgery, the use of ACE inhibitors should be considered a relative contraindication given the failure rate compared to those who are managed with ARBs.

\section{Bisphosphonates}

Bisphosphonates are a standard line of pharmacologic prevention and treatment for osteoporosis through suppression of bone turnover, causing adequate maintenance of BMD. Common bisphosphonates prescribed include etidronate, alendronate, risedronate, pamidronate, clodronate, tiludronate, ibandronate, and zoledronate. ${ }^{66}$ Bisphosphonates bind to hydroxyapatite in the bone and these skeletal binding abilities can vary between patients. ${ }^{67,68}$ The use of bisphosphonates is associated with a reduced fracture risk between 3 and 5 years of use, with discontinuation of treatment considered due to risk of rare, adverse effects such as osteonecrosis of the jaw and atypical femoral neck fractures. ${ }^{67,68}$ The estimated incidence of serious adverse effects is less than one case per 100,000 person-years of exposure to bisphosphonates. ${ }^{69}$ While the long-term benefits are currently unknown, multiple studies conclude that the reduced fracture incidence, maintenance of BMD, and reduction in bone turnover markers remain effective years after discontinuation of treatment. ${ }^{70,71}$ Implementing a drug holiday during the years of delayed dissipation of bisphosphonate effects can combat the adverse complications of long-term use while retaining osteoporotic shielding. ${ }^{72}$

\section{Denosumab}

Denosumab combats osteoporosis through direct inhibition of the activity of osteoclasts by blocking the receptor activator of nuclear factor kappa-B ligand binding to the receptor activator of nuclear factor kappa-B and has been considered effective with minimal safety risks. ${ }^{73}$ Candidates for denosumab include postmenopausal women diagnosed with osteoporosis, women currently taking aroma- tase inhibitors, and men at higher risk for osteoporotic fracture, including those on androgen deprivation therapy. ${ }^{74}$ The drug is given biannually as a single injection and while it functions in reducing the risk of osteoporotic fractures, an increased risk of infection can occur, and adverse effects of osteonecrosis of the jaw and atypical femoral fractures have been observed. ${ }^{75}$ The FREEDOM trial extension demonstrated that over a course of 10 years, serious adverse effects of denosumab were less frequent than 0.1 per 100 participant years. ${ }^{76}$ Furthermore, denosumab use in patients at 10 years resulted in consistent BMD increases with low fracture risks while maintaining low risk of adverse events. ${ }^{76}$ However, when used in patients with malignancy, the rate of serious adverse effects may be as high as $15 \%{ }^{69}$ Denosumab also demonstrated superior effects on BMD when compared to alendronate in phase I, II, and III trials. ${ }^{75}$ It is recommended that physicians reevaluate each patient every 5 years to determine whether continuation of denosumab is beneficial or whether transition to another therapy such as bisphosphonates can control bone turnover in a low-risk osteoporotic population. ${ }^{77}$

\section{Raloxifene}

Raloxifene is an estrogen receptor modulator that functions in prevention of osteoporotic fractures in postmenopausal women. Raloxifene acts similarly to estrogen on bone through inhibiting osteoclast activity and stimulating osteoblast activity to collectively maintain BMD. ${ }^{78}$ The use of raloxifene in patients with an established diagnosis of osteoporosis can limit bone turnover and increase BMD in the spine. It has also been shown to bind to the estrogen receptors in breast tissue antagonistically and can reduce the risk of cardiovascular events in high-risk patients. ${ }^{79,80}$ Candidates for raloxifene include postmenopausal women that are at risk for vertebral fractures or those with prior incidence of vertebral fracture; contraindications for use of raloxifene include history of deep venous thrombosis, pulmonary embolism, or stroke. ${ }^{81}$

\section{Teriparatide}

Teriparatide is a recombinant form of PTH and induces an anabolic effect on osteoblasts. Standard therapy includes daily injection with a recommended maximum use of 2 years until the long-term efficacy is established. ${ }^{74}$ Once injected, serum 
calcium rises within the first 8 hours to a normal range and the average increase of calcium excretion has been determined to be $32 \mathrm{mg} / \mathrm{d}{ }^{82}$ Teriparatide has been shown to increase BMD, subsequently reduce fracture risk, and facilitate the bone-implant interface in preclinical spinal fusion studies. ${ }^{83}$ Teriparatide has been investigated in clinical studies, concluding that its use results in a lower rate of implant loosening and that pedicle screw insertion intraoperatively required more torque for those prescribed teriparatide preoperatively. ${ }^{84,85}$ Contraindications for teriparatide include those with a prior diagnosis of Paget disease, osteosarcoma, or skeletal metastases. Mild adverse effects of teriparatide include dizziness, leg cramps, and hypercalciuria. $^{86}$

\section{Calcitonin}

Calcitonin is hormone that directly regulates serum calcium through its antiresorptive properties when binding to osteoclasts. Patients who are diagnosed with Paget disease, hypercalcemia, and osteoporosis are common candidates for calcitonin. While calcitonin is an effective medication in managing osteoporosis through minimizing bone turnover markers and maintenance of a normal BMD, patient compliance can be counteractive in reducing osteoporotic fracture risk. ${ }^{87,88}$ Common forms of delivery can be tablets or nasal spray of either human calcitonin or recombinant salmon calcitonin that shows comparable efficacy in maintenance of BMD. ${ }^{87,88}$ Associated side effects of calcitonin include nausea, vomiting, and abdominal pain.

\section{Special Surgical Considerations}

Patients with osteoporosis require special considerations when being evaluated for surgical intervention. Lehman et al ${ }^{89}$ cite that patients greater than 70 years of age with osteoporosis have about a $20 \%$ incidence of vertebral compression fractures. Preoperative planning is paramount when a patient with a diagnosis of osteoporosis has a fracture and/ or deformity that warrants surgical intervention, or deemed a surgical candidate secondary to failed conservative management or instability.

In evaluating the patient for elective surgical intervention, Lehman et $\mathrm{al}^{89}$ as well as Karikari and $\mathrm{Metz}^{8}$ recommend initiation of medical management prior to surgical intervention with the appropriate form of osteoporosis treatments. By doing so, one can optimize the patient and control for preoperative risks that may be contributed to osteoporotic diagnosis. Appropriate imaging, including but not limited to full axis radiographs can aid in not only planning the correct type of surgery, but also in correction of any deformity. In addition, optimization of preoperative risk factors can reduce the incidence of postoperative complication of pseudarthrosis, according to Karikari and Metz. ${ }^{8}$

Surgical planning consists of determining the size of the pedicle screw diameter and length, assessing the possibility of augmentation, and optimizing technique to limit screw migration, loosening, and pullout. Tandon et $\mathrm{al}^{90}$ reported $62 \%$ of screw loosening in the osteoporotic spine, with complications also including pullout and migration due to micromotion or injuries. Traditional methods of improving pedicle screw fixation stabilization according to Liu et $\mathrm{al}^{91}$ include increasing screw length, increasing the diameter of the screw, expanding the screw, and using augmentation such as polymethyl methacrylate (PMMA) in conjunction with pedicle screw fixation. McCoy et al ${ }^{92}$ also reviewed different modifications to aid in fixation, such as multiple points of fixation, cross-links, varied equipment such as laminar hooks, and modified trajectories. All these factors play an important role in surgical planning in the setting of osteoporosis due to the patient's poor bone quality. In the osteoporotic patient, osteoblastic activity is reduced and there is poor vascularity and lower bone marrow quality. ${ }^{90}$ Thus, the aforementioned leads to longer than usual periods of stress for instrumentation as it is used for temporary stabilization while awaiting fusion. To limit complications, Tandon et $\mathrm{al}^{90}$ proposed a modified surgical technique on bicortical fixation, referred to as 3-point fixation, using PMMA augmentation and bicortical fixation. This surgical intervention not only is proposed to limit above complications, but also to reduce the bicortical disadvantage of the "windshield-wiper effect," which can lead to pedicle fracture or screw bending. ${ }^{90}$ For this technique, the pedicle awl or burr is used to open the superficial cortex, and under image guidance, the trajectory is visualized down the isthmus, with care taken not to breach the anterior cortex. ${ }^{90}$ The size of the screw is chosen so that less than $2 \mathrm{~mm}$ of the screw courses the anterior cortex of the vertebral body. ${ }^{90}$ Next, a bone-filling device is inserted into prepared pedicle at a distance of the middle half of the vertebral body. Once the appropriate distance reached, a 
toothpaste-like consistency of PMMA ( $3 \mathrm{~mL}$ for lumbar spine; 2-2.5 $\mathrm{mL}$ for thoracic spine) is injected into the bone-filling device under fluoroscopy. ${ }^{90}$ After filling is completed, the device is removed, and the screw is immediately placed. In the study by Tandon et $\mathrm{al}^{90}$ a more medial angulation and larger-diameter screw were used in patients and there were no intraoperative complications and postoperatively there was no screw loosening or migration. When evaluating the visual analog scale and Oswestry disability index at 18month follow-up, both showed improvement using this surgical method. ${ }^{90}$ In addition, pullout strength increased to $120 \%$ from $31 \%$ with just bicortical screw placement, and from $250 \%$ to $119 \%$ with addition of PMMA. ${ }^{90}$ Care must be taken when using PMMA as it can result in exothermic necrosis, inability to integrate into surrounding bone, and difficult screw removal, if necessary. ${ }^{90}$

In a similar fashion, Liu et $\mathrm{al}^{91}$ evaluated cementaugmented pedicle screws (CAPS) and bone cementinjectable cannulated pedicle screws (CICPS). CICPS have a hollow screw rod with 3 side holes for bone cement outflow at the tip; as such, care must be taken to ensure no cement leakage. ${ }^{91}$ Leakage of cement has been shown to result in pulmonary embolus, paraplegia, and/or death. When using the CAPS system, the proximal side hole is the outflow for the bone cement; thus, the closer this side is to the screw head, the more significant the increase of pullout force, but conversely, the higher the risk of leakage into the spinal canal. ${ }^{91}$ As such, these authors arrange the holes from small to large on the anterior two-fifths of the screw, which they propose both allows for more outflow from the distal side and creates a more evenly distributed cement into the vertebral body. ${ }^{91}$ In reviewing the use of CAPS, only 3 controlled studies have been performed, all demonstrated decreased screw loosening. ${ }^{91}$ However, it is clear that more studies comparing CAPS with other forms of augmentation would be beneficial, especially regarding the osteoporotic spine.

Another consideration is points of fixation for the osteoporotic spine, specifically in the setting of deformity. Lehman et $\mathrm{al}^{89}$ show that at least 3-point fixation above and below the apex of the deformity is best for correction and stabilization. Anterior column support should be used whenever possible as it has demonstrated increased load sharing and decreased strain on the construct. ${ }^{89}$ Karikari and
Metz $^{8}$ highlight that, during the surgical procedure, care should be taken not to overtap, but to err on side of undertapping as this showed an increase in the insertion torque and pullout strength of pedicle screws. Karikari and $\mathrm{Metz}^{8}$ also demonstrated that undertapping by $0.5-1 \mathrm{~mm}$, or not tapping, resulted in significantly stronger screw pullout strength. ${ }^{8}$ Battula et $\mathrm{al}^{93}$ found that creating a pilot hole no larger than $71.5 \%$ of the outer diameter of the screw minimizes pullout and iatrogenic fracture. In regard to the distance the pedicle screws are inserted, it is recommended that hubbing be avoided as it affects pullout strength. ${ }^{93}$

The most significant contributor to failure in the osteoporotic spine is the bone-implant interface and thus, the trajectory of the pedicle screw insertion needs to be evaluated both pre- and intraoperative1y. ${ }^{89}$ Overall, medially angulated pedicle screws coupled with a transverse connector and length of $80 \%$ of the vertebral body been shown to improve pullout strength. ${ }^{89}$ Lehman et $\mathrm{al}^{89}$ found that in the thoracic spine, the maximum insertional torque and pullout strength is increased with a straight and forward directionality rather than anatomical trajectory. Regarding screw type, expandable screws have been shown to decrease risk of loosening when used in the lumbar spine; however, the US Food and Drug Administration does not currently approve these screw types. As such, more studies need to be undertaken to validate usage. ${ }^{8}$ In relation to expandable screws, Karikari and $\mathrm{Metz}^{8}$ illustrated that these work by compressing the cancellous bone within the vertebral bone as they expand, which increases the density of bone around the screw. ${ }^{8}$ Karikari and $\mathrm{Metz}^{8}$ also illustrated and recommended use of large-diameter, longer pedicle screws at multiple fixation points especially in long-fusion constructs. Reinforcement of screws with the addition of sublaminar wires or laminar hooks can accentuate the strength of fixation by increasing the pullout strength stiffness and torsion stability in osteoporotic bones.

Intraoperative achievement of spino-pelvic balance is an important goal in the surgical management of lumbar degenerative deformity. It is also recommended to incorporate iliac and/or tricortical sacral fixation in lumbosacral fusion to decrease risk of sacral insufficiency fractures. ${ }^{94}$ Tricortical sacral screw placement is achieved with trajectory towards the sacral promontory and is shown to have twice the strength of bicortical screws. ${ }^{94}$ Distal pelvic 
Table 3. Compiled risk factors appreciated in the peri- and postoperative setting of spine surgery for osteoporotic patients as well as independent risk factors. Anticipating these risk factors can help guide postoperative care of these patients in preventing falls. ${ }^{104}$

\begin{tabular}{|c|c|c|}
\hline Risk Factor & OR & $\mathbf{R R}$ \\
\hline Previous falls & & $1.9-6.6,1.8-2.1$ \\
\hline Age $>70$ & 2.2 & \\
\hline Balance impairment & & $1.2-2.4$ \\
\hline Decreased muscle strength & & $2.2-2.6$ \\
\hline Visual impairment & & $1.5-2.3$ \\
\hline $\begin{array}{l}\text { Polypharmacy (more than } 4 \text { medications) } \\
\text { or psychoactive drugs }\end{array}$ & & $1.1-2.4$ \\
\hline Gait impairment/walking difficulty & & $1.2-2.2$ \\
\hline Depression & & $1.5-2.8$ \\
\hline Dizziness or orthostatic hypotension & 2.0 & \\
\hline Functional limitations & & $1.1-6.2$ \\
\hline Female sex & & $2.1-3.9$ \\
\hline Low body mass index & & $1.5-1.8$ \\
\hline Urinary incontinence & & $1.3-1.8$ \\
\hline Cognitive impairment & 2.8 & \\
\hline Arthritis & & $1.2-1.9$ \\
\hline Diabetes & 3.8 & \\
\hline Pain & 1.7 & \\
\hline Vertigo & 5.3 & \\
\hline Stroke & 2.7 & \\
\hline Functional impairment & 1.7 & \\
\hline Sleep disturbance & 2.4 & \\
\hline Carpet floor & 8.3 & \\
\hline Use of a wheelchair & 1.2 & \\
\hline
\end{tabular}

Abbreviations: OR, odds ratio; $\mathrm{RR}$, relative risk.

fixation also helps to increase stability and decrease risk of pseudarthrosis and implant failure. ${ }^{94} \mathrm{~S} 2$ alar iliac screws may offer advantages over traditional sacral screws as they decrease the complication rate and lower implant prominence. ${ }^{87,94}$ Anterior stabilization or a combination of anterior with posterior stabilization has also been shown to increase construct stability and decrease subsidence by increasing cross-sectional area of an interbody graft. However, there have been some reports of increased risk of pseudarthrosis or cage subsidence with the anterior approach and this should be considered intraoperatively. ${ }^{87}$ Placement of the cage without invading the endplate ring may help prevent some of these complications. ${ }^{87,94}$ Positive sagittal alignment biomechanically places excessive strain on posterior instrumentation and fusion mass and contributes to instrumentation failure and pseudarthrosis, especially in the osteoporotic spine. ${ }^{94}$ Thus, a positive sagittal balance significantly increases the risk of developing pseudarthrosis.

Creation of good surface area with decortications and adequate bone grafting with rich vascular supply are keys in the formation of solid fusion mass. Choice of bone graft material plays significant role, with autologous iliac crest bone still being considered the gold standard because of osteogenic, osteoinductive, and osteoconductive properties.
However, there is significant morbidity and limited supply in regard to the iliac crest. As such, BMP auto-inductive factor in bone and recombinant human bone morphogenetic protein 2 osteo-biological device are now being used. ${ }^{8}$ Furthermore, need for use of these products needs to be evaluated by the surgeon. In the osteoporotic patient, there are numerous factors that the surgeon must take into consideration pre-, intra-, and postoperatively once the patient is deemed an appropriate candidate for intervention (Table 3).

\section{Special Postoperative Considerations}

\section{Bracing}

Lumbar bracing has been shown to reduce acute back pain, providing external immobilization after surgery; however, it has not been shown to help in preventing back injury or new onset of back pain. ${ }^{94}$ Support for bracing is founded in the idea of limiting spinal range of motion and correcting posture to promote bone healing, improve fusion rates, and offer pain relief. However, the disadvantages of bracing include dysphagia, nerve palsies, pressure ulcers, skin rashes, truncal muscle atrophy, and an economic burden. Furthermore, the efficacy of bracing is under reasonable scrutiny. ${ }^{95}$

Zhu et $\mathrm{al}^{95}$ undertook a recent systematic literature review of postoperative bracing following spine surgery. The outcomes measured to assess bracing efficacy were postoperative pain and functional outcomes, radiographic outcomes, cost effectiveness, and safety profile of postoperative bracing in the cervical spine and lumbar spine. ${ }^{96-99}$ It is worth noting that this review did not focus on an osteoporotic population. In osteoporotic patients, late complications include pseudarthrosis, instrumentation failure, adjacent-level degeneration, screw loosening, progressive kyphosis, and compression fractures. ${ }^{24,89}$ In the $\mathrm{Zhu}$ et al ${ }^{95}$ review, the only risk factor found to be recorded in all studies was age. In all the studies, the average age was under 65 , except for one study, where the average age was 72.9 years. Smoking status was followed in only 2 studies and in both studies was less than $50 \%$ of the patients. ${ }^{96,99}$ Furthermore, Zhu et $\mathrm{al}^{95}$ generalized findings that may not necessary align with the osteoporotic patient population.

Evaluation of postoperative pain and functional outcomes was measured by patient-reported surveys including the neck disability index, short form 36, and physical component score. The current litera- 
ture demonstrates that there is no clear evidence suggesting advantages or disadvantages to postoperative bracing with regard to postoperative pain or function. ${ }^{95-99}$ Evaluation of radiographic outcomes was measured with fusion rates reported in patients who either did or did not receive postoperative bracing. All current studies from this review of literature find no significant difference in bracing versus not bracing postoperatively in the cervical spine. ${ }^{95}$ Similarly, in the lumbar spine, Yee et al ${ }^{99}$ provided level 1 evidence that postoperative bracing offers no functional or radiographic benefit at 1 or 2 years after surgery. ${ }^{94,99}$ The safety profile was determined by reviewing complications, need for revision surgery or second procedure, and occurrence of myelopathy or radiculopathy postoperatively. Complications consisted of rates of instrumentation failure, graft extrusion, and necessity for bone stimulators, as well as surgical site infection, epidural hematomas, and C5 palsy. ${ }^{97,98}$ In the cervical spine no significant difference was appreciated between the 2 groups. In the lumbar spine there was no advantage or disadvantage noted in postoperative bracing. ${ }^{95,99}$ Based on this review, the use of postoperative bracing on degenerative lumbar disease has no impact on pain, disability, functional impairment, quality of life, radiographic outcomes, incidence of complications, and rate of reoperations. There were no studies on cost effectiveness for postoperative bracing that met the inclusion criteria for this review. ${ }^{95}$

These results may reflect that advancements in internal stabilization of the spine have reduced a need for postoperative bracing. There is level II evidence suggesting that the use of postoperative bracing following posterior lumbar interbody fusion is not supported. ${ }^{94}$ There are many who advocate for bracing, but there has been no clear evidence postoperative bracing works to increase fusion rates. $^{8,100-102}$ Although Johnsson et $\mathrm{al}^{102}$ demonstrated changes sagittal and vertical translation between 3 and 6 months of bracing with roentgen stereophotogrammetric analysis, they were not able to demonstrate evidence of improvement in lumbar spinal fusion or functional outcome with bracing. ${ }^{94,102}$ In the absence of evidence, the American Academy of Orthopedic Surgeons' Clinical Practice Guidelines are unable to give recommendations regarding bracing in postoperative care on in the event of osteoporotic vertebral compression fracture without any neurologic deficits. ${ }^{103}$
It is noted that in instances of poor bone quality, as in the case of osteoporosis, internal fixation may fail, leading to higher risks of nonunion or pseudarthrosis. ${ }^{100}$ In this patient population, there may still be a role in postoperative bracing. ${ }^{95,101}$ In vitro models have demonstrated a clear relationship between BMD and interbody graft stability. ${ }^{104}$ Pilliar et a ${ }^{105}$ demonstrated that movements greater than $150 \mu \mathrm{m}$ have deleterious effects to healing and fusion rates in trabecular bone.

\section{Fall Prevention}

Falls are associated with significant morbidity and complications in the osteoporotic population. Aging has been shown to be a major risk factor for both osteoporosis and falling. One third of the population older than 65 years falls annually and half of those individuals have recurrent falls. ${ }^{106,107}$ Falls should be considered in the perioperative and postoperative periods of management as the most common complications of spine surgery in osteoporotic patients include pedicle fractures and compression fractures. ${ }^{24,89}$ Furthermore it is important to understand the risk factors for postoperative falls in the osteoporotic patient as well as their prevention.

Demontiero et $\mathrm{al}^{106}$ have compiled a list of independent risk factors as well as risk factors in the postoperative period for falls with associated relative risks and odds ratios from literature review. Most of the risk factors involve the patient's medical history and functional status; however, there are some environmental factors to consider, such as presence of carpeting. Nursing or observation during this period is of utmost importance and should be completed with vigilance. There are currently 3 nursing assessment tools, which include the Morse fall scale, the St Thomas risk assessment tool in falling elderly inpatients, and the Hendrich fall risk model. Although some studies have found these surveys to show relatively low specificity and sensitivity, these are the current validated systems for monitoring fall risk in postoperative patients. ${ }^{108-110}$ In the postoperative setting, balancing pain with the sedative effects of analgesia and polypharmacy must be managed closely as these medications are associated with risk of falling. Pain should be targeted so that early mobilization may be encouraged to prevent deconditioning and delirium. Deconditioning, primarily in the knee extensors and knee flexors has demonstrated an increase in fall risk 
by 5 -fold. ${ }^{111}$ Delirium is also associated with lower functional recovery 1 year after fracture. ${ }^{15}$ Studies have demonstrated that orthogeriatric teams specialized in comprehensive geriatric assessment, management, and rehabilitation have decreased duration of delirium and reduced hospital stay times as well as rate of falls. ${ }^{106-108}$

\section{CONCLUSION}

This review aims to discuss the key points and nuances involved in spine surgery considerations of the osteoporotic patient. Preoperative evaluation includes making the diagnosis with appropriate screening, including but not limited to the appropriate radiographs, endocrinologist referral as necessary, and initiating pharmacologic therapy when applicable to optimize the osteoporotic patient. Preoperative planning is key because osteoporotic patient outcomes may include complications such as increased rates of proximal junctional kyphosis, pseudarthrosis, and distal pedicle screw loosening. In order to reduce incidence of these complications, surgeons have found success in increasing the diameter and length of pedicle screws, limiting pedicle tapping, ensuring spino-pelvic stabilization, augmenting with polymethyl methacrylate, preventing positive sagittal balance, and using adequate fusion products when necessary. In addition, postoperative management, including early mobilization, adequate pain management, and reliable monitoring, can help decrease postoperative complications, especially as they are related to falls.

Current practices in spine surgery have developed concomitantly with evidence-based medicine. However, upon completing this review, it is evident that there may still be some gaps in management on osteoporotic patients undergoing spine surgery. It may be useful to further investigate HU value as an appropriate screening tool for osteoporotic patients undergoing spine surgery. Though there are many pharmacological options in management of osteoporosis, there is no clear indication if standardization of therapy should be used. In regard to surgical options, there are many technical additions, such as expandable screws, that lack research for use. Finally, there are currently inadequate data on the role of bracing in osteoporotic patients who have undergone spinal fusion and should be further investigated. Osteoporosis is a commonly encountered comorbidity, which will only increase as the population ages, in patients undergoing spine surgery. Therefore, it is of utmost important to not only consider all aspects of their surgical care from a multidisciplinary standpoint, but to ensure that all areas of care are fully researched so as to optimize the patient as a whole.

\section{REFERENCES}

1. Silverman S. The clinical consequences of vertebral compression fracture. Bone. 1992;13(suppl 2):S27-S31.

2. Eastell R, Lambert H. Plenary lecture: strategies for skeletal health in the elderly. Proc Nutr Soc. 2009;61(2):173180 .

3. Alexandru D. Evaluation and management of vertebral compression fractures. Permanente J. 2012;16(4):46-51.

4. Park SB, Chung CK. Strategies of spinal fusion on osteoporotic spine. J Korean Neurosurg Soc. 2011;49(6):317322.

5. Kendler DL, Bauer DC, Davison KS, et al. Vertebral fractures: clinical importance and management. Am J Med. 2016;129(2):221.e221-221.e210.

6. Kanis JA. Diagnosis and clinical aspects of osteoporosis. In: Ferrari SL, Roux C, eds. Pocket Reference to Osteoporosis. Springer. 2019:11-20.

7. Almeida M, Laurent MR, Dubois V, et al. Estrogens and androgens in skeletal physiology and pathophysiology. Physiol Rev. 2017;97(1):135-187.

8. Karikari IO, Metz LN. Preventing pseudoarthrosis and proximal junctional kyphosis: how to deal with the osteoporotic spine. Neurosurg Clin N Am. 2018;29(3):365-374.

9. Okuda S, Oda T, Miyauchi A, Haku T, Yamamoto T, Iwasaki M. Surgical outcomes of posterior lumbar interbody fusion in elderly patients. J Bone Joint Surg Am. 2006;88(12):2714-2720.

10. Lane JM, Nydick M. Osteoporosis: current modes of prevention and treatment. $J$ Am Acad Orthop Surg. 1999;7(1):19-31.

11. American College of Radiology, the Society for Pediatric Radiology, and the Society of Skeletal Radiology. ACR-SPRSSR practice parameter for the performance of dual-energy $\mathrm{x}$ ray absorptiometry (DXA). https://www.acr.org/-/media/ACR/ Files/Practice-Parameters/DXA.pdf. Accessed April 6, 2020.

12. Link TM. Radiology of osteoporosis. Can Assoc Radiol J. 2016;67(1):28-40.

13. Steinmetz MP, Benzel EC. Benzel's Spine Surgery. Vol 1. Elsevier; 2016

14. Inose $\mathrm{H}$, Yamada $\mathrm{T}$, Mulati $\mathrm{M}$, et al. Bone turnover markers as a new predicting factor for nonunion after spinal fusion surgery. Spine. 2018;43(1):E29-E34.

15. Unnanuntana A, Gladnick BP, Donnelly E, Lane JM. The assessment of fracture risk. J Bone Joint Surg Am. 2010;92(3):743-753.

16. Wahner HW, Dunn WL, Brown ML, Morin RL, Riggs BL. Comparison of dual-energy x-ray absorptiometry and dual photon absorptiometry for bone mineral measurements of the lumbar spine. Mayo Clin Proc. 1988;63(11):1075-1084.

17. Mindways Software, Inc. QCT vs. DXA: What's the score? https://www.qct.com/Downloads/Whitepaper20130402_online.pdf. Accessed April 6, 2020.

18. Kim KJ, Kim DH, Lee JI, Choi BK, Han IH, Nam KH. Hounsfield units on lumbar computed tomography for predict- 
ing regional bone mineral density. Open Med (Wars). 2019;14:545-551.

19. Wittenberg RH, Shea M, Swartz DE, Lee KS, White AA 3rd, Hayes WC. Importance of bone mineral density in instrumented spine fusions. Spine (Phila Pa 1976). 1991;16(6):647-652.

20. DenOtter TD, Schubert J. Hounsfield unit. In: StatPearls. Treasure Island, FL. StatPearls Publishing; 2021.

21. Prevention and management of osteoporosis. $W H O$ Tech Rep Ser. 2003;921:1-164, back cover.

22. Yedavally-Yellayi S, Ho AM, Patalinghug EM. Update on osteoporosis. Prim Care: Clin Office Pract. 2019;46(1):175190.

23. Donnally IC, DiPompeo CM, Varacallo M. Vertebral compression fractures. In: StatPearls. Treasure Island, FL. 2020 .

24. DeWald CJ, Stanley T. Instrumentation-related complications of multilevel fusions for adult spinal deformity patients over age 65: surgical considerations and treatment options in patients with poor bone quality. Spine (Phila Pa 1976). 2006;31(19 suppl):S144-151.

25. Guzman JZ, Feldman ZM, McAnany S, Hecht AC, Qureshi SA, Cho SK. Osteoporosis in cervical spine surgery. Spine (Phila Pa 1976). 2016;41(8):662-668.

26. Mirza F, Canalis E. Management of endocrine disease: secondary osteoporosis: pathophysiology and management. Eur $J$ Endocrinol. 2015;173(3):R131-151.

27. Lekamwasam S, Adachi JD, Agnusdei D, et al. A framework for the development of guidelines for the management of glucocorticoid-induced osteoporosis. Osteoporos Int. 2012;23(9):2257-2276.

28. Abrahamsen B, Jorgensen HL, Laulund AS, et al. The excess risk of major osteoporotic fractures in hypothyroidism is driven by cumulative hyperthyroid as opposed to hypothyroid time: an observational register-based time-resolved cohort analysis. J Bone Miner Res. 2015;30(5):898-905.

29. Sinnesael M, Claessens F, Boonen S, Vanderschueren D. Novel insights in the regulation and mechanism of androgen action on bone. Curr Opin Endocrinol Diabetes Obes. 2013;20(3):240-244.

30. Chiang C, Chiu M, Moore AJ, et al. Mineralization and bone resorption are regulated by the androgen receptor in male mice. J Bone Miner Res. 2009;24(4):621-631.

31. Danilovic DL, Correa PH, Costa EM, Melo KF, Mendonca BB, Arnhold IJ. Height and bone mineral density in androgen insensitivity syndrome with mutations in the androgen receptor gene. Osteoporos Int. 2007;18(3):369-374.

32. Haider A, Meergans U, Traish A, et al. Progressive improvement of $\mathrm{T}$-scores in men with osteoporosis and subnormal serum testosterone levels upon treatment with testosterone over six years. Int J Endocrinol. 2014;2014:496948.

33. Kacker R, Conners W, Zade J, Morgentaler A. Bone mineral density and response to treatment in men younger than 50 years with testosterone deficiency and sexual dysfunction or infertility. J Urol. 2014;191(4):1072-1076.

34. D'Amelio P, Grimaldi A, Di Bella S, et al. Estrogen deficiency increases osteoclastogenesis up-regulating $\mathrm{T}$ cells activity: a key mechanism in osteoporosis. Bone. 2008;43(1):92100.

35. Levin VA, Jiang X, Kagan R. Estrogen therapy for osteoporosis in the modern era. Osteoporos Int. 2018;29(5):10491055 .
36. Black DM, Rosen CJ. Postmenopausal osteoporosis. $N$ Engl J Med. 2016;374(21):2096-2097.

37. Napoli N, Chandran M, Pierroz DD, et al. Mechanisms of diabetes mellitus-induced bone fragility. Nat Rev Endocrinol. 2017;13(4):208-219.

38. Wongdee K, Charoenphandhu N. Osteoporosis in diabetes mellitus: possible cellular and molecular mechanisms. World J Diabetes. 2011;2(3):41-48.

39. Catalfamo DL, Calderon NL, Harden SW, Sorenson HL, Neiva KG, Wallet SM. Augmented LPS responsiveness in type 1 diabetes-derived osteoclasts. J Cell Physiol. 2013;228(2):349-361.

40. Li CI, Liu CS, Lin WY, et al. Glycated hemoglobin level and risk of hip fracture in older people with type 2 diabetes: a competing risk analysis of Taiwan diabetes cohort study. $J$ Bone Miner Res. 2015;30(7):1338-1346.

41. Vestergaard P. Discrepancies in bone mineral density and fracture risk in patients with type 1 and type 2 diabetes - a meta-analysis. Osteoporos Int. 2007;18(4):427-444.

42. Hofbauer LC, Brueck CC, Singh SK, Dobnig H. Osteoporosis in patients with diabetes mellitus. J Bone Miner Res. 2007;22(9):1317-1328.

43. Boot AM, van der Sluis IM, Krenning EP, de Muinck Keizer-Schrama SM. Bone mineral density and body composition in adolescents with childhood-onset growth hormone deficiency. Horm Res. 2009;71(6):364-371.

44. Holmer H, Svensson J, Rylander L, et al. Fracture incidence in GH-deficient patients on complete hormone replacement including GH. J Bone Miner Res. 2007;22(12):1842-1850.

45. Mazziotti G, Bianchi A, Bonadonna S, et al. Increased prevalence of radiological spinal deformities in adult patients with GH deficiency: influence of $\mathrm{GH}$ replacement therapy. $J$ Bone Miner Res. 2006;21(4):520-528.

46. Mazziotti G, Chiavistelli S, Giustina A. Pituitary diseases and bone. Endocrinol Metab Clin North Am. 2015;44(1):171-180.

47. Walker MD, Nishiyama KK, Zhou B, et al. Effect of low vitamin $\mathrm{D}$ on volumetric bone mineral density, bone microarchitecture, and stiffness in primary hyperparathyroidism. $J$ Clin Endocrinol Metab. 2016;101(3):905-913.

48. Weaver CM, Alexander DD, Boushey CJ, et al. Calcium plus vitamin D supplementation and risk of fractures: an updated meta-analysis from the National Osteoporosis Foundation. Osteoporos Int. 2016;27(1):367-376.

49. Seitz S, Koehne $\mathrm{T}$, Ries $\mathrm{C}$, et al. Impaired bone mineralization accompanied by low vitamin $\mathrm{D}$ and secondary hyperparathyroidism in patients with femoral neck fracture. Osteoporos Int. 2013;24(2):641-649.

50. Bischoff-Ferrari HA, Dawson-Hughes B, Baron JA, et al. Calcium intake and hip fracture risk in men and women: a meta-analysis of prospective cohort studies and randomized controlled trials. Am J Clin Nutr. 2007;86(6):1780-1790.

51. Bolland MJ, Leung W, Tai V, et al. Calcium intake and risk of fracture: systematic review. BMJ. 2015;351:h4580.

52. Boonen S, Lips P, Bouillon R, Bischoff-Ferrari HA, Vanderschueren D, Haentjens P. Need for additional calcium to reduce the risk of hip fracture with vitamin D supplementation: evidence from a comparative metaanalysis of randomized controlled trials. J Clin Endocrinol Metab. 2007;92(4):14151423.

53. Bellido T, Saini V, Pajevic PD. Effects of PTH on osteocyte function. Bone. 2013;54(2):250-257.

54. Xiong J, Piemontese M, Thostenson JD, Weinstein RS, 
Manolagas SC, O'Brien CA. Osteocyte-derived RANKL is a critical mediator of the increased bone resorption caused by dietary calcium deficiency. Bone. 2014;66:146-154.

55. Miao D, He B, Lanske B, et al. Skeletal abnormalities in PTH-null mice are influenced by dietary calcium. Endocrinology. 2004;145(4):2046-2053.

56. Berger C, Greene-Finestone LS, Langsetmo L, et al. Temporal trends and determinants of longitudinal change in 25hydroxyvitamin $\mathrm{D}$ and parathyroid hormone levels. $J$ Bone Miner Res. 2012;27(6):1381-1389.

57. Bonjour JP, Benoit V, Payen F, Kraenzlin M. Consumption of yogurts fortified in vitamin $\mathrm{D}$ and calcium reduces serum parathyroid hormone and markers of bone resorption: a double-blind randomized controlled trial in institutionalized elderly women. J Clin Endocrinol Metab. 2013;98(7):2915-2921.

58. Ethgen O, Hiligsmann M, Burlet N, Reginster JY. Costeffectiveness of personalized supplementation with vitamin Drich dairy products in the prevention of osteoporotic fractures. Osteoporos Int. 2016;27(1):301-308.

59. Rajaee SS, Kanim LE, Bae HW. National trends in revision spinal fusion in the USA: patient characteristics and complications. Bone Joint J. 2014;96-B(6):807-816.

60. Perdomo-Pantoja A, Shamoun F, Holmes C, et al. A retrospective cohort analysis of the effects of renin-angiotensin system inhibitors on spinal fusion in ACDF patients. Spine $J$. 2019;19(8):1354-1361.

61. Kwok T, Leung J, Zhang YF, et al. Does the use of ACE inhibitors or angiotensin receptor blockers affect bone loss in older men? Osteoporos Int. 2012;23(8):2159-2167.

62. Ruths S, Bakken MS, Ranhoff AH, Hunskaar S, Engesaeter LB, Engeland A. Risk of hip fracture among older people using antihypertensive drugs: a nationwide cohort study. BMC Geriatr. 2015;15:153.

63. Butt DA, Mamdani M, Gomes T, et al. Risk of osteoporotic fractures with angiotensin II receptor blockers versus angiotensin-converting enzyme inhibitors in hypertensive community-dwelling elderly. J Bone Miner Res. 2014;29(11):2483-2488.

64. Kwok T, Leung J, Barrett-Connor E. ARB users exhibit a lower fracture incidence than ACE inhibitor users among older hypertensive men. Age Ageing. 2017;46(1):57-64.

65. Solomon DH, Mogun H, Garneau K, Fischer MA. Risk of fractures in older adults using antihypertensive medications. J Bone Miner Res. 2011;26(7):1561-1567.

66. WHO Scientific Group on the Prevention and Management of Osteoporosis. Prevention and management of osteoporosis: report of a WHO scientific group. https://apps.who.int/ iris/handle/10665/42841. Accessed April, 5, 2020.

67. McClung M, Harris ST, Miller PD, et al. Bisphosphonate therapy for osteoporosis: benefits, risks, and drug holiday. Am J Med. 2013;126(1):13-20.

68. Black DM, Bauer DC, Schwartz AV, Cummings SR, Rosen CJ. Continuing bisphosphonate treatment for osteoporosis-for whom and for how long? $N$ Engl J Med. 2012;366(22):2051-2053.

69. Wutzl A, Kirschke J, Mitchell D, Krestan C, Mücke T. Bisphosphonate and medication-related osteonecrosis of the jaw: a review. Semin Musculoskelet Radiol. 2016;20(03):305314.

70. Black DM, Reid IR, Cauley JA, et al. The effect of 6 versus 9 years of zoledronic acid treatment in osteoporosis: a randomized second extension to the HORIZON-Pivotal Fracture Trial (PFT). J Bone Miner Res. 2015;30(5):934-944.

71. Eriksen EF, Diez-Perez A, Boonen S. Update on longterm treatment with bisphosphonates for postmenopausal osteoporosis: a systematic review. Bone. 2014;58:126-135.

72. Adams AL, Adams JL, Raebel MA, et al. Bisphosphonate drug holiday and fracture risk: a population-based cohort study. J Bone Miner Res. 2018;33(7):1252-1259.

73. Eastell R, Christiansen C, Grauer A, et al. Effects of denosumab on bone turnover markers in postmenopausal osteoporosis. J Bone Miner Res. 2011;26(3):530-537.

74. Schweser KM, Crist BD. Osteoporosis: a discussion on the past 5 years. Curr Rev Musculoskelet Med. 2017;10(2):265274.

75. Bone HG, Chapurlat R, Brandi ML, et al. The effect of three or six years of denosumab exposure in women with postmenopausal osteoporosis: results from the FREEDOM extension. J Clin Endocrinol Metab. 2013;98(11):4483-4492.

76. Bone HG, Wagman RB, Brandi ML, et al. 10 years of denosumab treatment in postmenopausal women with osteoporosis: results from the phase 3 randomised FREEDOM trial and open-label extension. Lancet Diabetes Endocrinol. 2017;5(7):513-523.

77. Tsourdi E, Langdahl B, Cohen-Solal M, et al. Discontinuation of denosumab therapy for osteoporosis: a systematic review and position statement by ECTS. Bone. 2017; 105:11-17.

78. Gizzo S, Saccardi C, Patrelli TS, et al. Update on raloxifene: mechanism of action, clinical efficacy, adverse effects, and contraindications. Obstet Gynecol Surv. 2013;68(6):467-481.

79. Barrett-Connor E, Grady D, Sashegyi A, et al. Raloxifene and cardiovascular events in osteoporotic postmenopausal women: 4-year results from the MORE (multiple outcomes of raloxifene evaluation) randomized trial. JAMA. 2002;287(7):847-857.

80. Delmas PD, Ensrud KE, Adachi JD, et al. Efficacy of raloxifene on vertebral fracture risk reduction in postmenopausal women with osteoporosis: 4-year results from a randomized clinical trial. $J$ Clin Endocrinol Metab. 2002;87(8):3609-3617.

81. Visvanathan K, Chlebowski RT, Hurley P, et al. American Society of Clinical Oncology clinical practice guideline update on the use of pharmacologic interventions including tamoxifen, raloxifene, and aromatase inhibition for breast cancer risk reduction. J Clin Oncol. 2009;27(19):32353258 .

82. Miller PD, Bilezikian JP, Diaz-Curiel $\mathrm{M}$, et al. Occurrence of hypercalciuria in patients with osteoporosis treated with teriparatide. $J$ Clin Endocrinol Metab. 2007;92(9):3535-3541.

83. Chaudhary N, Lee JS, Wu JY, Tharin S. Evidence for use of teriparatide in spinal fusion surgery in osteoporotic patients. World Neurosurg. 2017;100:551-556.

84. Ohtori $\mathrm{S}$, Inoue $\mathrm{G}$, Orita $\mathrm{S}$, et al. Comparison of teriparatide and bisphosphonate treatment to reduce pedicle screw loosening after lumbar spinal fusion surgery in postmenopausal women with osteoporosis from a bone quality perspective. Spine (Phila Pa 1976). 2013;38(8):E487-492.

85. Inoue $G$, Ueno $M$, Nakazawa $T$, et al. Teriparatide increases the insertional torque of pedicle screws during fusion surgery in patients with postmenopausal osteoporosis. $J$ Neurosurg Spine. 2014;21(3):425-431. 
86. Lewiecki EM, Miller PD, Harris ST, et al. Understanding and communicating the benefits and risks of denosumab, raloxifene, and teriparatide for the treatment of osteoporosis. $J$ Clin Densitom. 2014;17(4):490-495.

87. Binkley N, Bolognese M, Sidorowicz-Bialynicka A, et al. A phase 3 trial of the efficacy and safety of oral recombinant calcitonin: the oral calcitonin in postmenopausal osteoporosis (ORACAL) trial. J Bone Miner Res. 2012;27(8):1821-1829.

88. Binkley N, Bone H, Gilligan JP, Krause DS. Efficacy and safety of oral recombinant calcitonin tablets in postmenopausal women with low bone mass and increased fracture risk: a randomized, placebo-controlled trial. Osteoporos Int. 2014;25(11):2649-2656.

89. Lehman RA Jr, Kang DG, Wagner SC. Management of osteoporosis in spine surgery. $J$ Am Acad Orthop Surg. 2015;23(4):253-263.

90. Tandon V, Kalidindi KKV, Pacha S, Bhat MR. A prospective study on the feasibility, safety, and efficacy of a modified technique to augment the strength of pedicle screw in osteoporotic spine fixation. Asian Spine J. 2020;14(3):357-363.

91. Liu YY, Xiao J, Yin X, et al. Clinical efficacy of bone cement-injectable cannulated pedicle screw short segment fixation for lumbar spondylolisthesis with osteoporosis. Sci Rep. 2020;10(1):3929.

92. McCoy S, Tundo F, Chidambaram S, Baaj AA. Clinical considerations for spinal surgery in the osteoporotic patient: a comprehensive review. Clin Neurol Neurosurg. 2019;180:40-47.

93. Battula S, Schoenfeld AJ, Sahai V, Vrabec GA, Tank J, Njus GO. The effect of pilot hole size on the insertion torque and pullout strength of self-tapping cortical bone screws in osteoporotic bone. J Trauma. 2008;64(4):990-995.

94. Dailey AT, Ghogawala Z, Choudhri TF, et al. Guideline update for the performance of fusion procedures for degenerative disease of the lumbar spine. Part 14: brace therapy as an adjunct to or substitute for lumbar fusion. J Neurosurg Spine. 2014;21(1):91-101.

95. Zhu MP, Tetreault LA, Sorefan-Mangou F, Garwood P, Wilson JR. Efficacy, safety, and economics of bracing after spine surgery: a systematic review of the literature. Spine $J$. 2018;18(9):1513-1525.

96. Abbott A, Halvorsen M, Dedering A. Is there a need for cervical collar usage post anterior cervical decompression and fusion using interbody cages? A randomized controlled pilot trial. Physiother Theory Pract. 2013;29(4):290-300.

97. Campbell MJ, Carreon LY, Traynelis V, Anderson PA. Use of cervical collar after single-level anterior cervical fusion with plate: is it necessary? Spine (Phila Pa 1976). 2009;34(1):43-48.

98. Hida T, Sakai Y, Ito K, et al. Collar fixation is not mandatory after cervical laminoplasty: a randomized controlled trial. Spine (Phila Pa 1976). 2017;42(5):E253-E259.

99. Yee AJ, Yoo JU, Marsolais EB, et al. Use of a postoperative lumbar corset after lumbar spinal arthrodesis for degenerative conditions of the spine. A prospective randomized trial. J Bone Joint Surg Am. 2008;90(10):2062-2068.

100. Bible JE, Biswas D, Whang PG, Simpson AK, Rechtine GR, Grauer JN. Postoperative bracing after spine surgery for degenerative conditions: a questionnaire study. Spine $J$. 2009;9(4):309-316.
101. Connolly PJ, Grob D. Bracing of patients after fusion for degenerative problems of the lumbar spine-yes or no? Spine (Phila Pa 1976). 1998;23(12):1426-1428.

102 Johnsson R. The use of orthoses in lumbar spine fusion. Acta Orthop Scand Suppl. 1993;251:92-93.

103. McGuire R. AAOS Clinical Practice Guideline: The Treatment of Symptomatic Osteoporotic Spinal Compression Fractures. Am Acad Orthop Surg. 2011;19(3):183-184.

104. Lund T, Oxland TR, Jost B, et al. Interbody cage stabilisation in the lumbar spine: biomechanical evaluation of cage design, posterior instrumentation and bone density. $J$ Bone Joint Surg Br. 1998;80(2):351-359.

105. Pilliar RM, Lee JM, Maniatopoulos C. Observations on the effect of movement on bone ingrowth into porous-surfaced implants. Clin Orthop Relat Res. 1986(208):108-113.

106. Demontiero O, Gunawardene P, Duque G. Postoperative prevention of falls in older adults with fragility fractures. Clin Geriatr Med. 2014;30(2):333-347.

107. Deandrea S, Lucenteforte E, Bravi F, Foschi R, La Vecchia C, Negri E. Risk factors for falls in communitydwelling older people: a systematic review and meta-analysis. Epidemiology. 2010;21(5):658-668.

108. Oliver D, Papaioannou A, Giangregorio L, Thabane L, Reizgys K, Foster G. A systematic review and meta-analysis of studies using the STRATIFY tool for prediction of falls in hospital patients: how well does it work? Age Ageing. 2008;37(6):621-627.

109. Schwendimann R, De Geest S, Milisen K. Evaluation of the Morse Fall Scale in hospitalised patients. Age Ageing. 2006;35(3):311-313.

110. Vassallo M, Stockdale R, Sharma JC, Briggs R, Allen S. A comparative study of the use of 4 fall risk assessment tools on acute medical wards. J Am Geriatr Soc. 2005;53(6):10341038 .

111. Yau DT, Chung RC, Pang MY. Knee muscle strength and visual acuity are the most important modifiable predictors of falls in patients after hip fracture surgery: a prospective study. Calcif Tissue Int. 2013;92(3):287-295.

Disclosures and COI: The authors report no conflict of interest concerning the materials or methods used in this study or the findings specified in this paper. The authors have not received any funding for this work from any organization.

Corresponding Author: Brian Fiani, DO, Desert Regional Medical Center, 1180 N Indian Canyon Dr, Ste 214 W, Palm Springs, CA 92262. Phone: (760) 416-4511; Email: bfiani@outlook.com.

Published 16 April 2021

This manuscript is generously published free of charge by ISASS, the International Society for the Advancement of Spine Surgery. Copyright (C) 2021 ISASS. To see more or order reprints or permissions, see http://ijssurgery.com. 